\title{
A bifunctional ion-electron conducting interlayer for high energy density all-solid-state lithium-sulfur battery
}

\author{
Yuewu Zhu, Jie Li and Jin Liu* \\ School of Metallurgy and Environment, Central South University, \\ Changsha City, 410083, China \\ *Corresponding author: Jin Liu \\ Email: jinliu@csu.edu.cn
}




\begin{abstract}
A bifunctional ion-electron conducting layer is designed for all-solid-state lithium-sulfur battery. This layer consists of electronic conductor and solid polymer electrolyte that is intercalated between the cathode and electrolyte. By forming a gradient of electrons and lithium ions, the electrochemical performance and interfacial compatibility of the battery are obviously enhanced. When a pure sulfur powder is directly used as an active material of the cathode, the battery delivers the initial discharge capacity of $1457 \mathrm{mAh} \mathrm{g}^{-1}$ and the discharge capacity of 792.8 $\mathrm{mAh} \mathrm{g}{ }^{-1}$ after 50 cycles at $0.5 \mathrm{C}$ and $80{ }^{\circ} \mathrm{C}$, while the battery with the same cathode and without the interlayer only has the discharge capacity of $291.9 \mathrm{mAh} \mathrm{g}^{-1}$ after the same number of cycles.
\end{abstract}

Keywords: ion-electron conductor; all-solid-state; lithium-sulfur battery; active material utilization; battery configuration 


\section{Introduction}

With rapid developments in advanced portable electronic devices, electric vehicles and energy storage systems, the demand for high energy density rechargeable batteries is continuously increasing [1-3]. The lithium-sulfur ( $\mathrm{Li}-\mathrm{S})$ battery is one of the most promising systems due to its high theoretical capacity of $1672 \mathrm{mAh} \mathrm{g}^{-1}[4,5]$. Moreover, elemental sulfur is a naturally abundant active cathode material that can reduce cost $[6,7]$.

Despite the obvious advantages of Li-S battery, the practicality is limited by inherent poor electronic conductivity of both sulfur and $\mathrm{Li}_{2} \mathrm{~S}$, dissolution of the intermediate lithium polysulfide species and the volume change during the discharge-charge process $[8,9]$. A variety of strategies such as elaborate designs of the cathode structure, optimization of the separator, specific additive of the electrolyte and anode protection have been employed to overcome the intrinsic problems [10-14]. In addition, new battery configurations by introducing an interlayer between the cathode and the separator showed higher sulfur utilization and better cycle life for liquid electrolyte lithium-sulfur batteries [15-22].

However, reliability and safety are still insufficient in conventional liquid Li-S batteries due to the dissolution of polysulfides and the formation of lithium dendrites. Thus, all-solid-state Li-S batteries employing solid electrolytes to replace liquid electrolytes are attracting 
intense research interest [23-25]. Especially, all-solid-state Li-S batteries based on solid polymer electrolytes (SPEs) possess extraordinary flexibility, enabling design and manufacture of stylish energy storage devices and electric vehicles [25-30].

Previous studies have found that PEO-based SPEs show high electrochemical performance. A poly(ethylene oxide)-lithium triflate (PEO-LiCF $\left.\mathrm{SO}_{3}\right)$ complex with nano-sized zirconia $\left(\mathrm{ZrO}_{2}\right)$ and lithium sulfide $\left(\mathrm{Li}_{2} \mathrm{~S}\right)$ was applied in all-solid-state $\mathrm{Li}-\mathrm{S}$ batteries. The initial discharge capacity was $900 \mathrm{mAh} \mathrm{g}^{-1}$ at $0.05 \mathrm{C}$ and $90{ }^{\circ} \mathrm{C}$ [25]. Lately, a metal-organic framework (MIL-53(Al)) modified SPE combined with a macro-structural sulfur cathode was used to inhibit polysulfide dissolution and shuttling in all-solid-state Li-S batteries [27]. After 1000 cycles at a current density of $4 \mathrm{C}$ and $80^{\circ} \mathrm{C}$, a discharge capacity of 325 $\mathrm{mAh} \mathrm{g}^{-1}$ was obtained. However, different from the liquid electrolyte, the solid electrolyte has difficultly infiltrating into the conductive matrix to maintain an integrated Li-ion conductive pathway. Since the electrochemical reaction takes place only when lithium ions and electrons contact the active materials $[31,32]$, the electronic and ionic conductivities must be balanced and improved [33].

Herein, we design and fabricate a bifunctional ion-electron conducting layer that is intercalated between the cathode and SPE. By forming a gradient change of electrons and lithium ions and constructing 
a structural similarity in electrode and electrolyte, the electrochemical performance and interfacial compatibility of the battery system are obviously improved. A pure sulfur powder can be directly used as the active material of the cathode without any modification. The all-solid-state Li-S battery delivers an initial discharge capacity of 1457 $\mathrm{mAh} \mathrm{g}^{-1}$ at $0.5 \mathrm{C}$ and $80{ }^{\circ} \mathrm{C}$. After 50 discharge/charge cycles, the battery maintains the discharge capacity of $792.8 \mathrm{mAh} \mathrm{g}^{-1}$ that is three times higher than one without the interlayer.

\section{Experimental section}

\subsection{Materials}

Sublimed sulfur ( $\mathrm{S}, 99.95 \%$ ), super $\mathrm{P}$, polyethylene oxide (PEO, $\left.\mathrm{M}_{\mathrm{w}}=4000000,99.9 \%\right)$, and acetonitrile $\left(\mathrm{CH}_{3} \mathrm{CN}\right.$, chromatographic grade) were obtained from Aladdin. Lithium bis(trifluoro-methanesulfonyl)imide (LiTFSI, +99.5\%) was purchased from Sigma Aldrich and stored in a glove box. N-Methyl-2-pyrrolidone (NMP, 99.5\%) was purchased from Heowns. Metal-organic-framework (MOF) of MIL-53(Al) was prepared as the previous report [34].

\subsection{Preparation of polymer membrane}

The preparation of the interlayer membrane was carried out as follows: PEO was dried at $60{ }^{\circ} \mathrm{C}$ for $24 \mathrm{~h}$ and LiTFSI was dried at $100{ }^{\circ} \mathrm{C}$ for $24 \mathrm{~h}$ in a vacuum oven before use. Firstly, $0.0500 \mathrm{~g}$ MIL-53(Al) nano-particles, $0.0500 \mathrm{~g}$ super $\mathrm{P}, 0.5000 \mathrm{~g}$ PEO and $0.2170 \mathrm{~g}$ LiTFSI 
were mixed in acetonitrile, and stirred to form a homogenized solution. After that, the solution was cast and dried into a thin film at $80{ }^{\circ} \mathrm{C}$ for 24 $\mathrm{h}$ in an argon-filled glove box. Finally, a black thin film interlayer was formed. The SPE was prepared according to our previous report [34]. The effects of super P concentrations (5, 10 and $20 \mathrm{wt} \%$ of the amount of PEO) on battery performance were investigated. The battery with $10 \mathrm{wt} \%$ super $\mathrm{P}$ shows the best cycling and rate performance. Thus, $10 \mathrm{wt} \%$ super $\mathrm{P}$ was used in the work.

\subsection{Electrochemical measurements of the membranes}

The electronic conductivities of the interlayer, the cathode composition and interlayer without LiTFSI were measured by four-point probes (RTS-8). For the SPE, the electronic conductivity was measured by the Hebb-Wagner polarization method using a (-)Li/SPE/stainless steel electrode(+) asymmetric cell [35]. The ionic conductivities of the SPE and interlayer were determined by AC impedance spectroscopy and chronoamperometry measurements by using a PARSTAT 4000 system. In the AC impedance spectroscopy method, the cells were tested over the frequency range between $500 \mathrm{kHz}$ to $10 \mathrm{~Hz}$ with perturbation amplitude of $10 \mathrm{mV}$. In the chronoamperometry measurements, polarization of the cells were carried out by a small voltage $(\Delta V)$ of $10 \mathrm{mV}$ and Nyquist spectra were obtained in the frequency between $500 \mathrm{kHz}$ and $0.1 \mathrm{~Hz}$ with an oscillation voltage of $10 \mathrm{mV}$ before polarization. 


\subsection{Battery performance}

Four kinds cathode composites were prepared by the blending method: $\quad \mathrm{S}_{60} \mathrm{C}_{30} \mathrm{PAA}_{10}, \quad \mathrm{~S}_{60} \mathrm{C}_{30} \mathrm{PAA}_{8} \mathrm{SPE}_{2}, \quad \mathrm{~S}_{60} \mathrm{C}_{30} \mathrm{PAA}_{5} \mathrm{SPE}_{5} \quad$ and $\mathrm{S}_{60} \mathrm{C}_{30} \mathrm{PAA}_{2} \mathrm{SPE}_{8}$ (the subscript means the mass ratio of the compositions in the cathode). To prepare the cathode materials, a certain proportion of elemental sulfur powder, PAA binder, carbon black (super P) and SPE were mixed in N-methylpyrrolidone (NMP). The homogeneously mixed slurry was cast onto an aluminum foil and dried at $50{ }^{\circ} \mathrm{C}$ for $24 \mathrm{~h}$ to remove the solvent. Cathode disks with a diameter of $10 \mathrm{~mm}(\mathrm{~S}=0.7854$ $\mathrm{cm}^{2}$ ), sulfur content of $60 \mathrm{wt} \%$ and average area sulfur loading of $0.7 \mathrm{mg}$ $\mathrm{cm}^{-2}$ were punched. Electrochemical testing was performed with CR2025 coin type batteries. The battery was assembled by contacting in sequence the cathode of $\mathrm{S}_{60} \mathrm{C}_{30} \mathrm{PAA}_{10}$, the interlayer, SPE, lithium metal foil anode $(\mathrm{d}=16.2 \mathrm{~mm})$, and nickel foam current collector. And the comparison battery was assembled by contacting in sequence the cathode of $\mathrm{S}_{60} \mathrm{C}_{30} \mathrm{PAA}_{10}, \mathrm{~S}_{60} \mathrm{C}_{30} \mathrm{PAA}_{8} \mathrm{SPE}_{2}, \mathrm{~S}_{60} \mathrm{C}_{30} \mathrm{PAA}_{5} \mathrm{SPE}_{5}$ or $\mathrm{S}_{60} \mathrm{C}_{30} \mathrm{PAA}_{2} \mathrm{SPE}_{8}$, SPE, lithium metal foil anode $(\mathrm{d}=16.2 \mathrm{~mm})$, and nickel foam current collector. All batteries were assembled in a controlled argon-filled box with both humidity and oxygen content below $1 \mathrm{ppm}$.

The batteries were tested by galvanostatic cycling in a 1.5-2.8 V voltage range by using a LAND battery-testing instrument (Wuhan Land Electronic Co., Ltd. China). Cyclic voltammetry (CV) and 
electrochemical impedance spectroscopy (EIS) measurements were conducted using a PARSTAT 4000 electrochemical measurement system. $\mathrm{CV}$ tests were performed at a scan rate of $0.2 \mathrm{mV} \mathrm{s}^{-1}$ in the voltage range of 1.5-2.8 V. EIS measurements were carried out at open-circuit potential (OCP) in the frequency range between $100 \mathrm{kHz}$ and $0.1 \mathrm{~Hz}$ with perturbation amplitude of $10 \mathrm{mV}$. Before all measurements, the batteries were kept at the given temperature for at least $4 \mathrm{~h}$ to reach thermal equilibrium.

\subsection{Physical and thermal characterization}

Morphologies of the MIL-53(Al) nanoparticle, super P and interlayer were observed with a scanning electron microscopy (SEM, sirion 200). The thermal behavior of the cathode and sublimed sulfur samples were investigated by a thermogravimetric analysis (TGA, SDTQ600) under an Ar atmosphere at a heating rate of $10{ }^{\circ} \mathrm{C} \mathrm{min}^{-1}$ from 30 to $800{ }^{\circ} \mathrm{C}$.

\section{Results and discussion}

\subsection{Configuration of Li-S battery, physical characteristics of interlayer and thermal stability of the cathode}

The all-solid-state Li-S battery configuration with the bifunctional ion-electron conducting interlayer is shown in Fig. 1a. The difference between the new configuration and traditional architecture is the introduction of the interlayer between the cathode and SPE. A pure sulfur 
powder is directly used as the active material of the cathode without any modification to study the effect of the interlayer on the electrochemical performance of the all-solid-state Li-S battery system. Fig. 1(b-d) displays the surface morphologies of the super $\mathrm{P}, \mathrm{MIL}-53(\mathrm{Al})$ and the interlayer, respectively. A network structure of the interconnected carbon black nanoparticles with less than $100 \mathrm{~nm}$ can be observed in Fig.1b. The rod-like morphology of the MIL-53(Al) (Fig.1c) is similar to the previous report [34]. A smooth surface of the interlayer is observed in Fig. 1d, which shows the carbon black, MIL-53(Al) and lithium salt are uniformly distributed in the interlayer without aggregation.

(a)

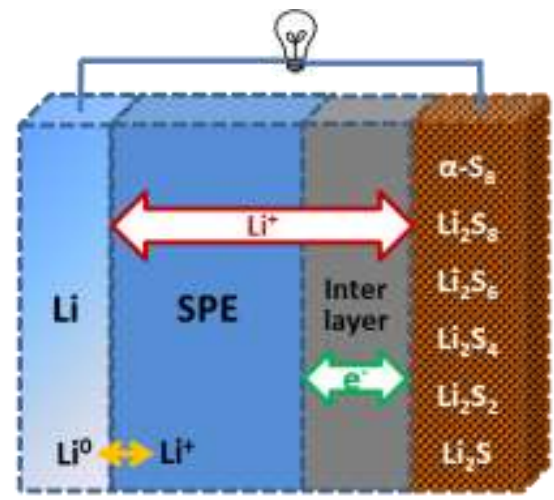

(c)

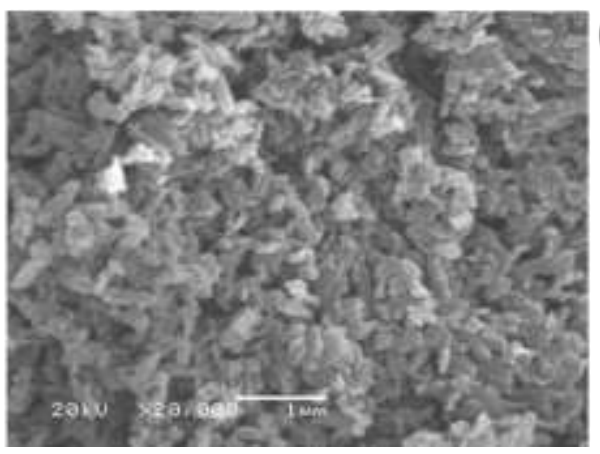

(b)

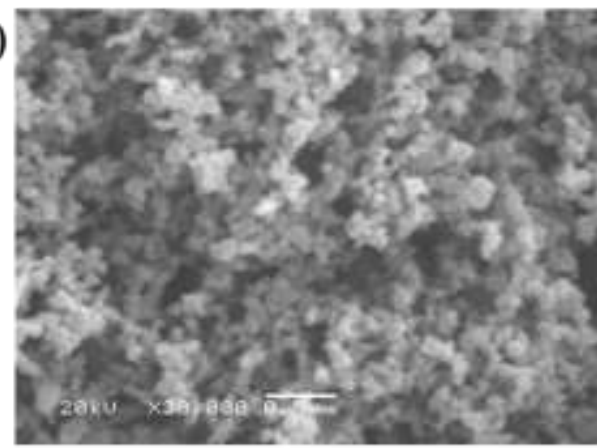

(d)

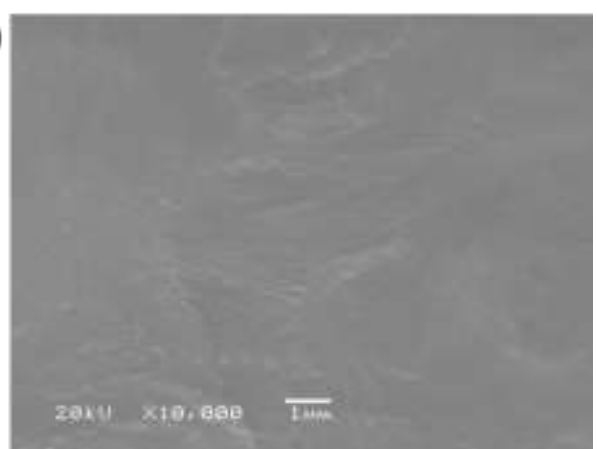

Fig. 1. (a) Schematic representation of the Li-S architecture with an interlayer. (b), (c) and (d) are SEM images of super P, MIL-53(Al) and interlayer, respectively.

In order to investigate the physical stability of the interlayer 
membrane at high temperature, the interlayer was heated at $80{ }^{\circ} \mathrm{C}$ for 16 hours and its pictures were taken and shown in Fig. 2. The prepared interlayer membrane (Fig. 2a) on a Telfon film was heated on a hotplate at $80{ }^{\circ} \mathrm{C}$ in the glove box filled with argon (Fig. 2b). After 3 hours (Fig. 2c), 5.5 hours (Fig. 2d), and overnight (Fig. 2e), the membrane can be still peeled off from the Telfon film (Fig. 2f). The interlayer membrane presents the same state as unheated and shows good flexibility and self-standing characters.

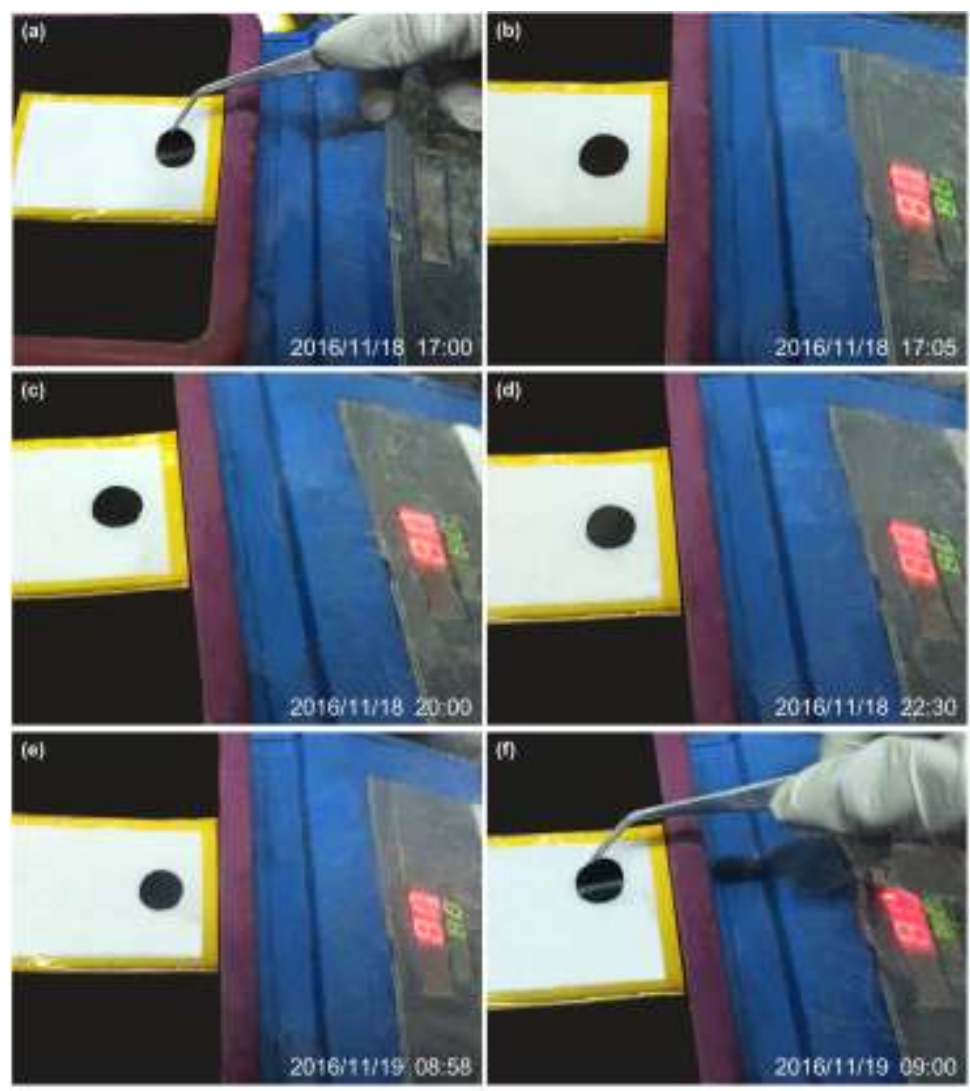

Fig. 2. Photos of the prepared interlayer (a), interlayer heated at $80{ }^{\circ} \mathrm{C}$ in the glove box filled with argon for $0 \mathrm{~h}$ (b), about $3 \mathrm{~h}$ (c), $5.5 \mathrm{~h}$ (d) and overnight (e), and peeled off from the heater (f).

Thermogravimetric analysis (TGA) was performed to investigate the thermal behavior of the $\mathrm{S}_{60} \mathrm{C}_{30} \mathrm{PAA}_{10}$ cathode sample in an Ar atmosphere 
at a heating rate of $10{ }^{\circ} \mathrm{C} \mathrm{min}^{-1}$ from 30 to $800{ }^{\circ} \mathrm{C}$. For comparison, the TGA experiment for the pure sulfur was also carried out, as shown in Fig. 3. Below $300^{\circ} \mathrm{C}$, the curves for the two samples are basically overlapped, which shows the weight loss of the sublimed sulfur. However, the first degradation of $63.0 \%$ in the cathode material is higher than the sulfur percentage $(60 \%)$ added in the cathode. This is due to the loss of absorbed water during the sample transfer $\left(\sim 1.5 \%\right.$ before $\left.200{ }^{\circ} \mathrm{C}\right)$ and partially decomposition of the binder poly(acrylic acid) (PAA) [36]. The remaining of $37.0 \%$ weight is chiefly ascribed to conductive carbon and PAA.

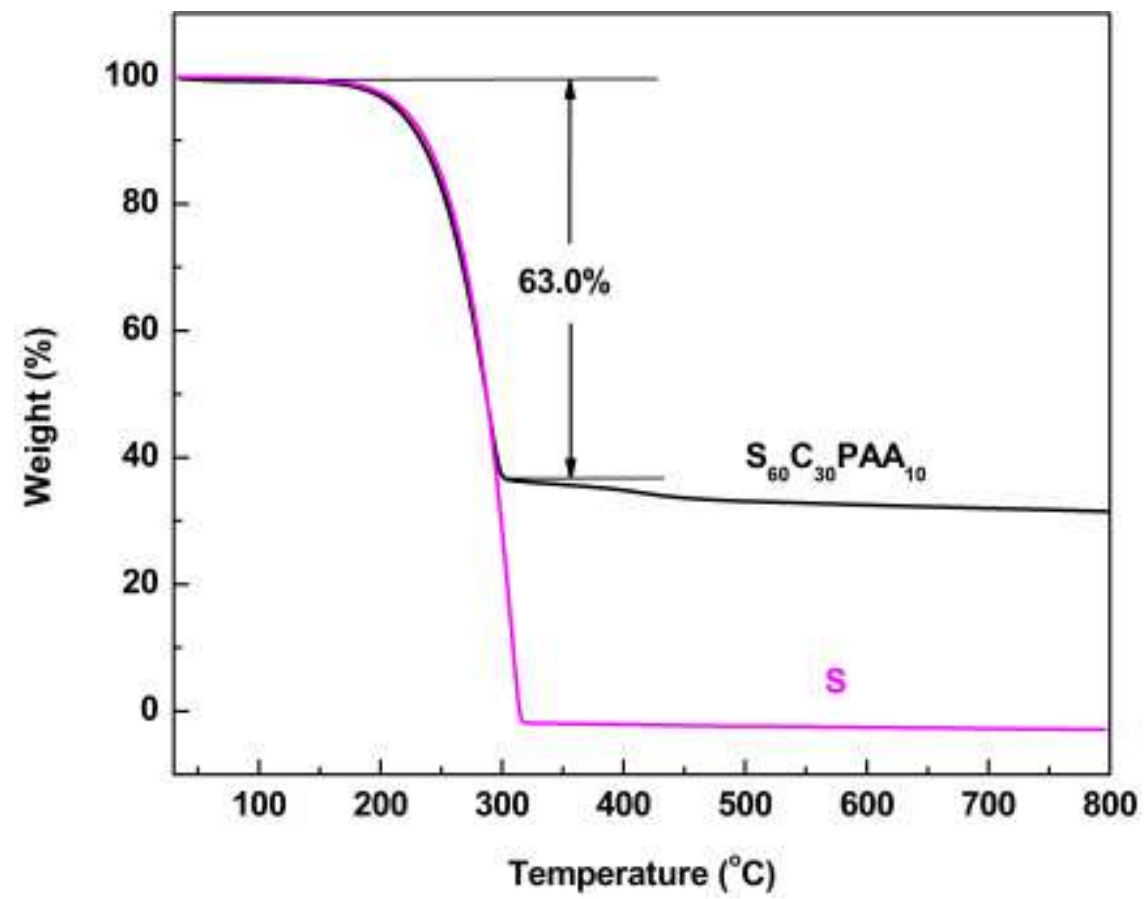

Fig. 3. TGA results of the $\mathrm{S}_{60} \mathrm{C}_{30} \mathrm{PAA}_{10}$ cathode and sublimed sulfur. The samples were heated at $10{ }^{\circ} \mathrm{C} \mathrm{min}^{-1}$ under $\mathrm{Ar}$ atmosphere.

\subsection{Electronic and ionic conductivities}

To confirm the electron-ion conducting properties of the interlayer, 
the electronic conductivities at room temperature were measured by four-probe and Hebb-Wagner polarization method, and the ionic conductivity was measured by $\mathrm{AC}$ impedance spectroscopy and direct current method (chronoamperometry). The electronic conductivity data at about $25{ }^{\circ} \mathrm{C}$ are summarized in Table 1 . For the cathode of $\mathrm{S}_{60} \mathrm{C}_{30} \mathrm{PAA}_{10}$, the addition of the carbon increases the electronic conductivity of pure sulfur dramatically $\left(3.89 \mathrm{~S} \mathrm{~cm}^{-1}\right.$ of the cathode vs. $5 \times 10^{-30} \mathrm{~S} \mathrm{~cm}^{-1}$ of pure sulfur). The electronic conductivity of the interlayer is distinctly higher than that of pure SPE $\left(10^{-4} \mathrm{~S} \mathrm{~cm}^{-1}\right.$ vs. $\left.10^{-11} \mathrm{~S} \mathrm{~cm}^{-1}\right)$. Because of the low electronic conductivity of the SPE, the SPE membrane was used to block the electron transport when the ionic conductivity of the interlayer was measured. The interlayer without LiTFSI has a similar electronic conductivity to the interlayer, indicating that LiTFSI has little influence on the electronic conductivity. As a result, the electronic conductivity gradually decreases from the cathode to the interlayer then to the SPE (from $3.89 \mathrm{~S} \mathrm{~cm}^{-1}$ to $6.89 \times 10^{-4} \mathrm{~S} \mathrm{~cm}^{-1}$ then to $2.52 \times 10^{-11} \mathrm{~S} \mathrm{~cm}^{-1}$ ).

Table 1 The electronic conductivities of the samples at $25^{\circ} \mathrm{C}$.

\begin{tabular}{cc}
\hline Samples & Electronic conductivity $\left(\mathrm{S} \mathrm{cm}^{-1}\right)$ \\
\hline $\mathrm{S}_{60} \mathrm{C}_{30} \mathrm{PAA}_{10}$ & 3.89 \\
Interlayer & $6.89 \times 10^{-4}$ \\
$\mathrm{SPE}$ & $2.52 \times 10^{-11}$ \\
Interlayer without LiTFSI & $9.07 \times 10^{-4}$ \\
\hline
\end{tabular}


AC impedance spectroscopy was used to measure the ionic conductivity of the SPE with a completely symmetric SS/SPE/SS cell. The impedance spectra present a semicircle at high frequency and a straight line at low frequency at low temperature and a linear trend over the entire examined frequency range at high temperature. The intercept of the $\mathrm{x}$-axis of the straight line is the SPE resistance $\left(R_{S P E}\right)$. So, the ionic conductivity can be calculated by the equation: $\sigma_{S P E}=l_{S P E} /\left(R_{S P E} \times S\right)$, where $l_{S P E}(0.02 \mathrm{~cm})$ is the thickness of the SPE membrane, and $S(2.07$ $\mathrm{cm}^{2}$ ) is the area of the stainless steel electrode.

The same test for the symmetric SS/SPE/interlayer electrolyte/SPE/SS (each SPE layer is $0.0015 \mathrm{~cm}$ ) was carried out to get the ionic conductivity of the interlayer. The two symmetric SPE layers were used to block the electron transport. So, the measured resistance is only from ions transport of the cell. The AC impedance spectra of the $\mathrm{SS} / \mathrm{SPE} /$ interlayer/SPE/SS cell at selected temperatures $(25,50,80$ and $100{ }^{\circ} \mathrm{C}$ ) are shown in Fig. 4a. The spectra present the same shape with that of the SS/SPE/SS cell. The intercept of the $\mathrm{x}$-axis of the straight line is the total resistance $\left(R_{\text {total }}\right)$ of the two SPE layers and the interlayer. The interlayer resistance $\left(R_{\text {interlayer }}\right)$ can be calculated by $R_{\text {total }}-2 R_{\mathrm{SPE}}$, where $R_{S P E}=l_{S P E} /\left(\sigma_{S P E} \times S\right)$ and $S$ is the area of the stainless steel electrode (2.07 $\left.\mathrm{cm}^{2}\right), l_{S P E}(0.0015 \mathrm{~cm})$ is the thickness of one SPE membrane. The ionic conductivity of the interlayer is calculated by the equation of $\sigma_{\text {interlayer }}=$ 
$l_{\text {interlayer }} /\left(R_{\text {interlayer }} \times S\right)$, where $l_{\text {interlayer }}(0.016 \mathrm{~cm})$ is the thickness of the interlayer membrane, and $S\left(2.07 \mathrm{~cm}^{2}\right)$ is the area of the stainless steel electrodes. The values of the ionic conductivities of the interlayer are calculated and presented in Fig. $4 \mathrm{~b}$, and the ionic conductivities of the SPE are also shown in Fig. $4 \mathrm{~b}$ for comparison. As can be shown, the interlayer shows a better ionic conductivity than the SPE. The ionic conduction behavior for both SPE and interlayer is basically divided into two parts. At low temperature (linear, crystalline phase) the data was fitted by the Arrhenius equation $\left(\sigma=\sigma_{0} \exp \left[E_{a} /(k T)\right]\right.$, where the $\sigma_{0}$ reflects the number of charge carriers, and $k$ stands for the Boltzmann constant, whereas $E_{a}$ reflects the activation energy), while the Vogel-Tammam-Fulcher (VTF) equation $\left(\sigma=\sigma_{0} T^{1 / 2} \exp \left[-B /\left(T-T_{0}\right)\right]\right.$, in which $B$ represents the apparent activation energy and can be replaced by $1000 E_{d} / R$, where $R$ is the gas constant) was used to fit the data at high temperature (non-linear curve, amorphous phase) [37]. Thus, the phase transition temperature can be measured at the crossing point of the two fitted lines, which are $49.7{ }^{\circ} \mathrm{C}$ and $50.7{ }^{\circ} \mathrm{C}$, respectively for the interlayer and the electrolyte. A relative low phase transition temperature of the interlayer is observed.

For the Arrhenius fit, the activation energy $E_{a}$ is reduced from 127.2 $\mathrm{kJ} \mathrm{mol}^{-1}$ in the SPE sample to $118.6 \mathrm{~kJ} \mathrm{~mol}^{-1}$ in the interlayer. For the VTF fit, the $E_{a}$ values for the SPE and interlayer are 1.96 and $1.79 \mathrm{~kJ}$ 
mol $^{-1}$, respectively. The different $E_{a}$ values in two temperature regions indicated the different ionic conduction process.

This enhanced ionic conductivity of the interlayer is mostly due to the interaction between the super $\mathrm{P}$ and SPE. Since electrons are negatively charged, the super P nanoparticles will strongly attract lithium ions and repel TFSI anions. This will provide a path for the ion transport under the attracting and discouraging edge of electric charge and facilitate the dissociation of lithium salt. Thus, the ionic conductivity of the interlayer is increased.
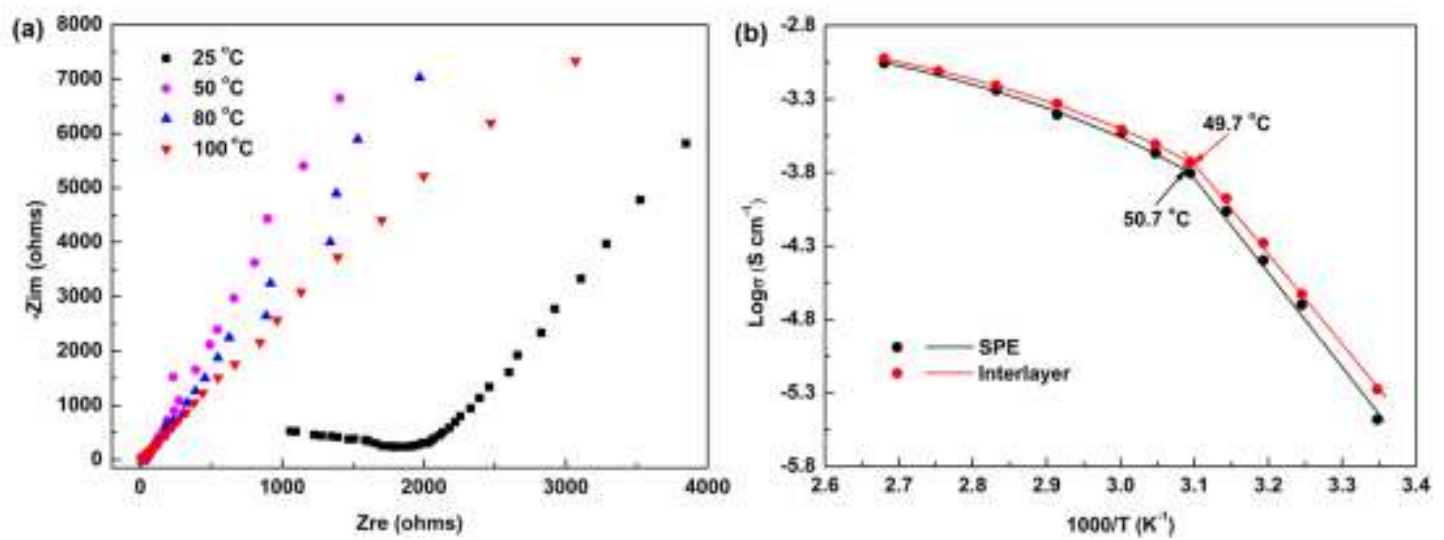

Fig. 4. (a) AC impedance spectra of the SS/SPE/interlayer/SPE/SS cell at 25, 50, 80 and $100{ }^{\circ} \mathrm{C}$. (b) Temperature dependency of ionic conductivities of the SPE and interlayer in the temperature range from 25 to $100{ }^{\circ} \mathrm{C}$. (The circles are the experimental data and the lines are the fitted results).

In addition, the direct current method with the symmetric cells ( $\mathrm{Li} / \mathrm{SPE} / \mathrm{Li}$ and $\mathrm{Li} / \mathrm{SPE} /$ interlayer/SPE/Li) was also used to measure ionic conductivities of the SPE and interlayer respectively at 50 and $80{ }^{\circ} \mathrm{C}$. The chronoamperometry plots and corresponding Nyquist spectra before polarization are shown in Fig. 5. 

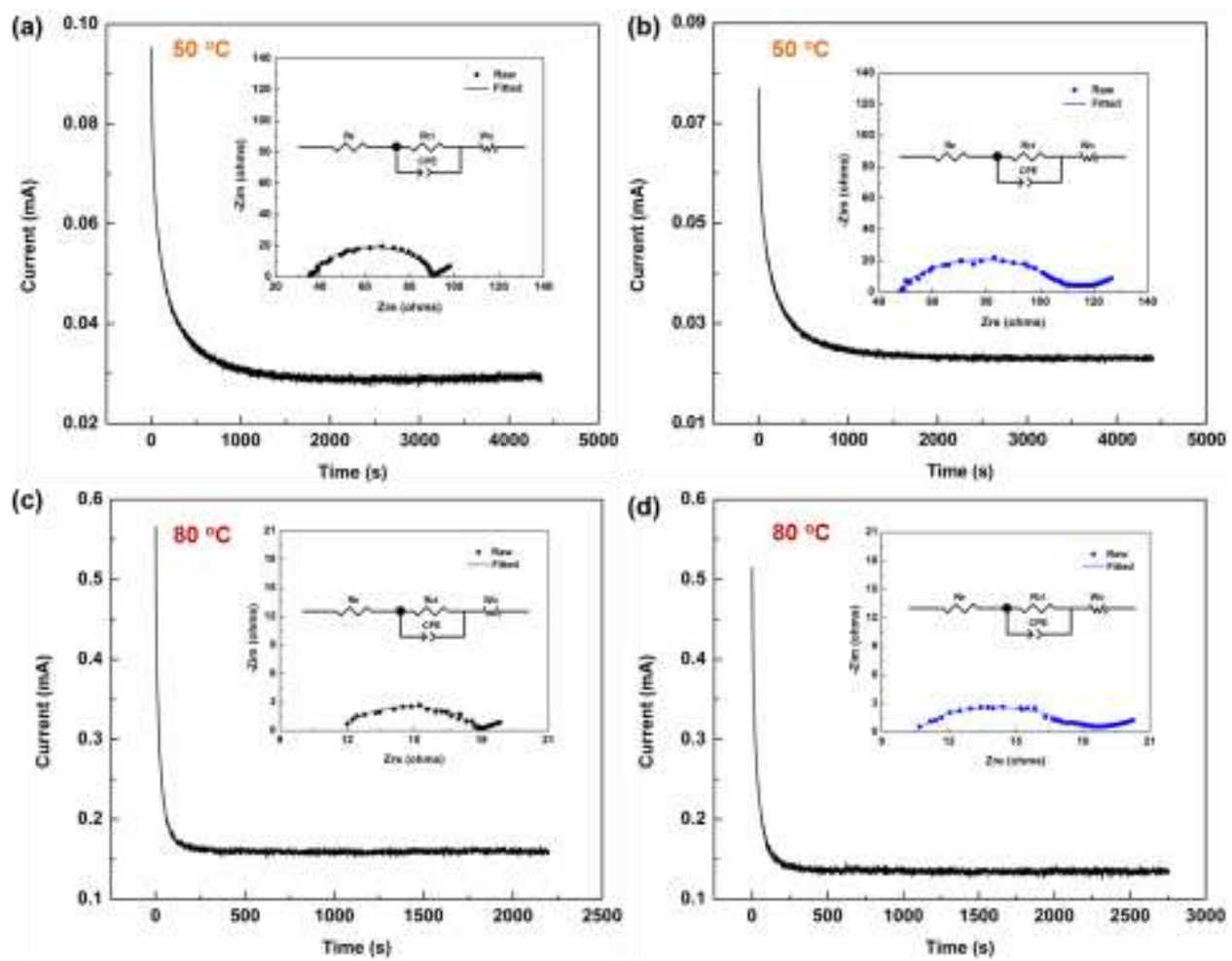

Fig. 5. Chronoamperometries of the $\mathrm{Li} / \mathrm{SPE} / \mathrm{Li}$ cell $(\mathrm{a}, \mathrm{c})$ and the $\mathrm{Li} / \mathrm{SPE} /$ interlayer/SPE/Li cell (b, d), respectively at 50 and $80{ }^{\circ} \mathrm{C}$. Inset: the AC impedance spectra for the cells and fitted by the equivalent circuit.

In the results of $\mathrm{Li} / \mathrm{SPE} / \mathrm{Li}$, the $\mathrm{SPE}$ resistance $\left(R_{S P E}\right)$ can be directly readout from the Nyquist spectrum, that is the starting point of the semicircle at high frequency, and it also can be calculated by the equation: $R_{S P E}=V / I_{0}-R_{0}$, where $V$ and $I_{0}$ is the initial voltage and current flowing through the cell, and $R_{0}$ represents the initial interfacial resistance value before polarization. So, the ionic conductivity can be calculated by the equation: $\sigma_{S P E}=l_{S P E} /\left(R_{S P E} \times S\right)$, where $l_{S P E}(0.016 \mathrm{~cm})$ is the thickness of the SPE membrane, and $S\left(2.07 \mathrm{~cm}^{2}\right)$ is the area of the lithium electrode. For the $\mathrm{Li} / \mathrm{SPE} /$ interlayer/SPE/Li cell, the value readout from the Nyquist spectrum is the total bulk resistance $\left(R_{\text {total }}\right)$, and the bulk resistance of the interlayer $\left(R_{\text {interlayer }}\right)$ can be calculated by $R_{\text {total }}-2 R_{S P E}$, where $R_{S P E}=l_{S P E}$ 
$/\left(\sigma_{S P E} \times S\right)$ and $S$ is the area of the lithium electrode, $l_{S P E}(0.002 \mathrm{~cm})$ is the thickness of one SPE membrane. And the bulk resistance of the interlayer $\left(R_{\text {interlayer }}\right)$ can also be calculated by $V / I_{0}-R_{0}-2 R_{S P E}$. The related parameters and values of ionic conductivities of the SPE and interlayer with four different cell structures (SS/SPE/SS, SS/SPE/interlayer/SPE/SS, $\mathrm{Li} / \mathrm{SPE} / \mathrm{Li}$ and $\mathrm{Li} / \mathrm{SPE} /$ interlayer/SPE$/ \mathrm{Li}$ ) at $50{ }^{\circ} \mathrm{C}$ and $80{ }^{\circ} \mathrm{C}$ are listed in

\section{Table 2.}

Table 2 The related parameters and values of the SPE and interlayer with four different cell structures (SS/SPE/SS, SS/SPE/interlayer/SPE/SS, Li/SPE/Li and Li/SPE/interlayer/SPE/Li) respectively at 50 and $80{ }^{\circ} \mathrm{C}$.

\begin{tabular}{|c|c|c|c|c|c|c|c|c|c|c|}
\hline $\begin{array}{l}\text { Samples } \\
\text { (Methods) }\end{array}$ & $\begin{array}{c}\mathrm{T} \\
\left({ }^{\circ} \mathrm{C}\right) \\
\end{array}$ & $\begin{array}{r}I_{0} \\
(\mu \mathrm{A}) \\
\end{array}$ & $\begin{array}{c}V \\
(\mathrm{mV}) \\
\end{array}$ & $\begin{array}{l}R_{0} \\
(\Omega)\end{array}$ & $\begin{array}{r}R_{S P E} \\
(\Omega) \\
\end{array}$ & $\begin{array}{c}R_{\text {interlayer }} \\
(\Omega)\end{array}$ & $\begin{array}{l}l_{S P E} \\
(\mathrm{~cm}) \\
\end{array}$ & $\begin{array}{c}l_{\text {interlayer }} \\
(\mathrm{cm})\end{array}$ & $\begin{array}{c}\sigma_{\mathrm{SPE}} \\
\left(\mathrm{S} \mathrm{cm}^{-1}\right)\end{array}$ & $\begin{array}{l}\sigma_{\text {interlayer }} \\
\left(\mathrm{S} \mathrm{cm}^{-1}\right)\end{array}$ \\
\hline SS/SPE/SS & 50 & - & 10 & - & 61.7 & - & 0.020 & - & $1.57 \times 10^{-4}$ & - \\
\hline (EIS) & 80 & - & 10 & - & 16.8 & - & 0.020 & - & $5.75 \times 10^{-4}$ & - \\
\hline SS/SPE/interlayer/SPE/SS & 50 & - & 10 & - & - & 41.6 & 0.0015 & 0.016 & - & $1.86 \times 10^{-4}$ \\
\hline (EIS) & 80 & - & 10 & - & - & 12.5 & 0.0015 & 0.016 & - & $6.19 \times 10^{-4}$ \\
\hline $\mathrm{Li} / \mathrm{SPE} / \mathrm{Li}$ & 50 & 95.2 & 9.584 & 53.0 & $47.7^{(\mathrm{c})}$ & - & 0.016 & - & $1.62 \times 10^{-4}$ & - \\
\hline (Chronoamperometry) & 50 & & & & $37.5^{(\mathrm{m})}$ & - & 0.016 & - & $2.06 \times 10^{-4}$ & - \\
\hline (Chronoamperometry) & 80 & 566 & 9.737 & 5.85 & $11.4^{(\mathrm{c})}$ & - & 0.016 & - & $6.78 \times 10^{-4}$ & - \\
\hline (Chronoamperometry) & 80 & & & & $11.8^{(\mathrm{m})}$ & - & 0.016 & - & $6.55 \times 10^{-4}$ & - \\
\hline $\mathrm{Li} / \mathrm{SPE} /$ interlayer/SPE/Li & 50 & 76.9 & 9.507 & 68.6 & - & $43.1^{(\mathrm{c})}$ & 0.002 & 0.016 & - & $1.79 \times 10^{-4}$ \\
\hline (Chronoamperometry) & 50 & & & & - & $40.6^{(\mathrm{m})}$ & 0.002 & 0.016 & - & $1.90 \times 10^{-4}$ \\
\hline (Chronoamperometry) & 80 & 514 & 9.891 & 6.60 & - & $9.79^{(\mathrm{c})}$ & 0.002 & 0.016 & - & $7.89 \times 10^{-4}$ \\
\hline (Chronoamperometry) & 80 & & & & - & $8.75^{(\mathrm{m})}$ & 0.002 & 0.016 & - & $8.83 \times 10^{-4}$ \\
\hline
\end{tabular}

Notes: the superscript of the $(\mathrm{m})$ and $(\mathrm{c})$ represents the measured and calculated values respectively.

The ionic conductivities of the SPE obtained by the EIS method are $1.57 \times 10^{-4} \mathrm{~S} \mathrm{~cm}^{-1}$ at $50{ }^{\circ} \mathrm{C}$ and $5.75 \times 10^{-4} \mathrm{~S} \mathrm{~cm}^{-1}$ at $80{ }^{\circ} \mathrm{C}$, which are close to the results measured by the chronoamperometry method (the calculated 
ionic conductivity of $1.62 \times 10^{-4} \mathrm{~S} \mathrm{~cm}^{-1}$ at $50{ }^{\circ} \mathrm{C}$ and $6.78 \times 10^{-4} \mathrm{~S} \mathrm{~cm}^{-1}$ at 80 ${ }^{\circ} \mathrm{C}$, and the measured results of $2.06 \times 10^{-4} \mathrm{~S} \mathrm{~cm}^{-1}$ at $50{ }^{\circ} \mathrm{C}$ and $6.55 \times 10^{-4} \mathrm{~S}$ $\mathrm{cm}^{-1}$ at $\left.80{ }^{\circ} \mathrm{C}\right)$. For the interlayer, the results obtained by the EIS method are $1.86 \times 10^{-4} \mathrm{~S} \mathrm{~cm}^{-1}$ at $50{ }^{\circ} \mathrm{C}$ and $6.19 \times 10^{-4} \mathrm{~S} \mathrm{~cm}^{-1}$ at $80{ }^{\circ} \mathrm{C}$ that are similar to the values measured by the chronoamperometry method (the calculated ionic conductivity of $1.79 \times 10^{-4} \mathrm{~S} \mathrm{~cm}^{-1}$ at $50{ }^{\circ} \mathrm{C}$ and $7.89 \times 10^{-4} \mathrm{~S}$ $\mathrm{cm}^{-1}$ at $80{ }^{\circ} \mathrm{C}$, and the measured results of $1.90 \times 10^{-4} \mathrm{~S} \mathrm{~cm}^{-1}$ at $50{ }^{\circ} \mathrm{C}$ and $8.83 \times 10^{-4} \mathrm{~S} \mathrm{~cm}^{-1}$ at $80{ }^{\circ} \mathrm{C}$ ). Hence, these results of the ionic conductivity of the SPE and interlayer are consistent with determined by the EIS and chronoamperometry methods.

\subsection{Electrochemical performance of all-solid-state Li-S batteries}

In order to investigate the effects of the interlayer and the electrolyte added into the cathode on battery electrochemical performance, the all-solid-state Li-S batteries were fabricated. The cycling performances of the batteries having the cathodes of $\mathrm{S}_{60} \mathrm{C}_{30} \mathrm{PAA}_{10}, \mathrm{~S}_{60} \mathrm{C}_{30} \mathrm{PAA}_{8} \mathrm{SPE}_{2}$, $\mathrm{S}_{60} \mathrm{C}_{30} \mathrm{PAA}_{5} \mathrm{SPE}_{5}$ and $\mathrm{S}_{60} \mathrm{C}_{30} \mathrm{PAA}_{2} \mathrm{SPE}_{8}$ without the interlayer as well as $\mathrm{S}_{60} \mathrm{C}_{30} \mathrm{PAA}_{10}$ with the interlayer at $80{ }^{\circ} \mathrm{C}$ and $0.5 \mathrm{C}$ are shown in Fig. $6 \mathrm{a}$. As can be seen, the battery with the cathode of $\mathrm{S}_{60} \mathrm{C}_{30} \mathrm{PAA}_{10}$ and the interlayer delivers an initial discharge capacity of $1457 \mathrm{mAh} \mathrm{g}^{-1}$, which is $87.1 \%$ of the theoretical capacity of sulfur $\left(1672 \mathrm{mAh} \mathrm{g}^{-1}\right)$. After 50 discharge/charge cycles, the capacity of $792.8 \mathrm{mAh} \mathrm{g}^{-1}$ maintains. By contrast, the battery based on $\mathrm{S}_{60} \mathrm{C}_{30} \mathrm{PAA}_{10}$ without the interlayer only has 
an initial discharge capacity of $209 \mathrm{mAh} \mathrm{g}^{-1}$, and a five-cycle activating process is needed to reach the maximum capacity of $626.6 \mathrm{mAh} \mathrm{g}^{-1}$.

Among the three cathodes contain different concentrations of SPE, the battery with the cathode of $\mathrm{S}_{60} \mathrm{C}_{30} \mathrm{PAA}_{5} \mathrm{SPE}_{5}$ shows the best cycling performance. But, this battery has lower capacities (the maximum discharge capacity of $703.7 \mathrm{mAh} \mathrm{g}^{-1}$ and the capacity of $421.8 \mathrm{mAh} \mathrm{g}^{-1}$ after 50 cycles) than that of $\mathrm{S}_{60} \mathrm{C}_{30} \mathrm{PAA}_{10}$ with the interlayer. Hence, these results demonstrate that the interlayer effectively improves the electrochemical performance of the all-solid-state Li-S batteries. 

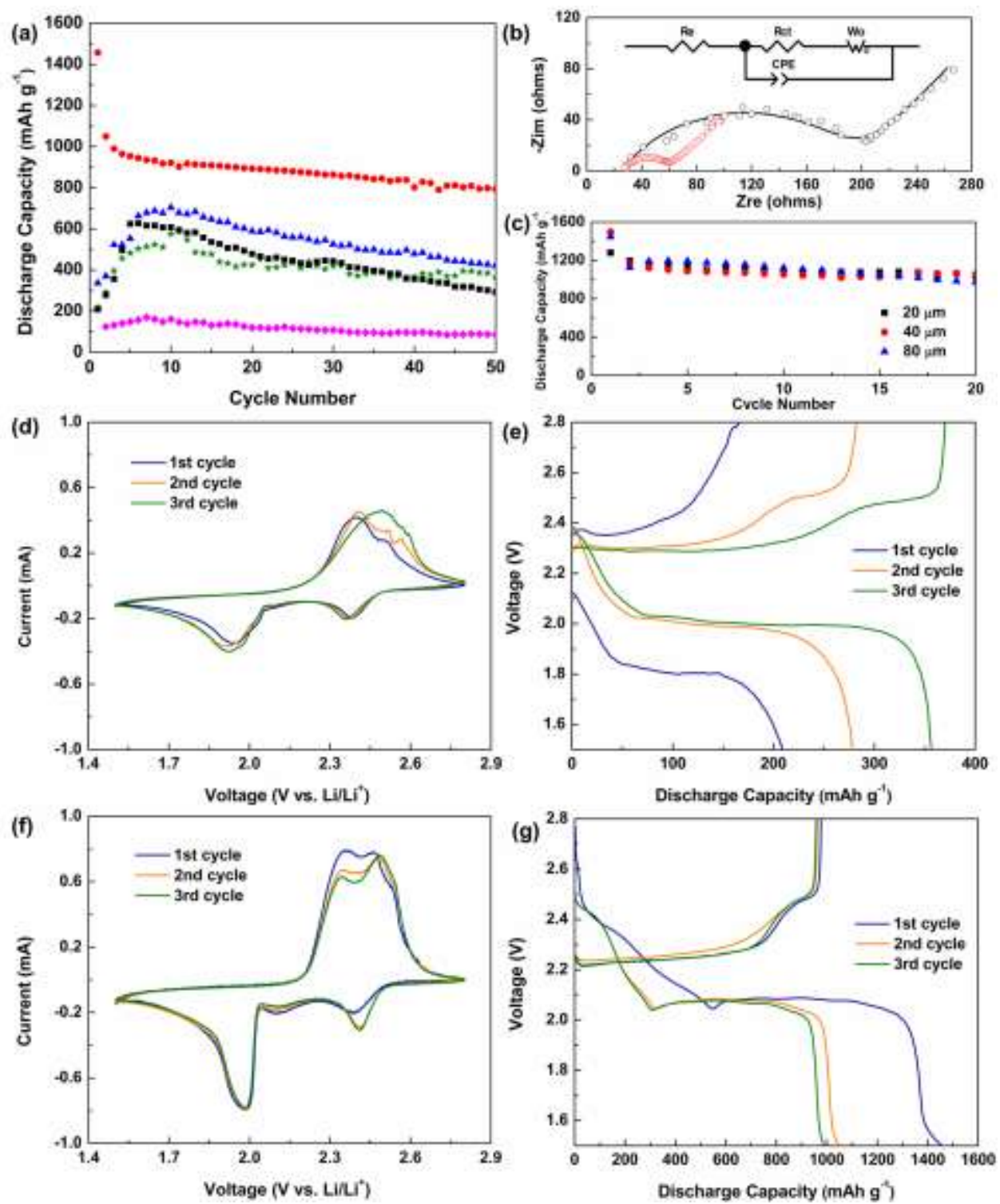

Fig. 6. Electrochemical data of the Li-S batteries: (a) Cycling performances of the batteries with different cathodes and with/without the interlayer at $0.5 \mathrm{C}$ and $80{ }^{\circ} \mathrm{C}$. Red circle: $\mathrm{S}_{60} \mathrm{C}_{30} \mathrm{PAA}_{10}$ with the interlayer, black square: $\mathrm{S}_{60} \mathrm{C}_{30} \mathrm{PAA}_{10}$ without the interlayer, olive star: $\mathrm{S}_{60} \mathrm{C}_{30} \mathrm{PAA}_{8} \mathrm{SPE}_{2}$ without the interlayer, blue triangle: $\mathrm{S}_{60} \mathrm{C}_{30} \mathrm{PAA}_{5} \mathrm{SPE}_{5}$ without the interlayer, and magenta diamond: $\mathrm{S}_{60} \mathrm{C}_{30} \mathrm{PAA}_{2} \mathrm{SPE}_{8}$ without the interlayer, where the SPE has the same compositions as the solid electrolyte films. (b) Nyquist plots of the batteries with the same cathode of $\mathrm{S}_{60} \mathrm{C}_{30} \mathrm{PAA}_{10}$ and without the interlayer (black) as well as with the interlayer (red) at $80{ }^{\circ} \mathrm{C}$. The scatter represents original data, and the line represents the fitting results by using the equivalent circuit in the inset. (c) Cycling performances of the Li-S batteries with the interlayer thicknesses of 20, 40 and $80 \mu \mathrm{m}$ at $0.2 \mathrm{C}$ and $80{ }^{\circ} \mathrm{C}$. (d) Cyclic voltammograms of the battery with $\mathrm{S}_{60} \mathrm{C}_{30} \mathrm{PAA}_{10}$ and without the interlayer at $80^{\circ} \mathrm{C}$. (e) The discharge-charge profiles of the battery with $\mathrm{S}_{60} \mathrm{C}_{30} \mathrm{PAA}_{10}$ and without the interlayer at $0.5 \mathrm{C}$ and $80{ }^{\circ} \mathrm{C}$. (f) Cyclic voltammograms of the battery with $\mathrm{S}_{60} \mathrm{C}_{30} \mathrm{PAA}_{10}$ and the interlayer at $80{ }^{\circ} \mathrm{C}$. (g) The discharge-charge profiles of the battery with $\mathrm{S}_{60} \mathrm{C}_{30} \mathrm{PAA}_{10}$ and the interlayer at $0.5 \mathrm{C}$ and $80{ }^{\circ} \mathrm{C}$ (the voltage range: $2.8-1.5 \mathrm{~V}$; the scan rate: 0.2 $\mathrm{mV} \mathrm{s}^{-1}$; and the current density of $1 \mathrm{C}: 1672 \mathrm{~mA} \mathrm{~g}^{-1}$ ). 
In order to understand the interlayer effect, EIS was used to measure the internal resistance of the batteries with the same cathode of $\mathrm{S}_{60} \mathrm{C}_{30} \mathrm{PAA}_{10}$ and with/without the interlayer at $80{ }^{\circ} \mathrm{C}$ (see Fig. $6 \mathrm{~b}$ ). The first interception of the curves with the $\mathrm{x}$-axis in the high frequency range is related to the bulk resistance [38], which is similar in the batteries with and without interlayer (26.35 $\Omega$ vs. $24.66 \Omega$ ). The diameter of the semicircular portions of the curves in the middle frequency range represents the charge transfer resistance $\left(R_{\mathrm{ct}}\right)$ [39], which provides the interfacial information at the electrode/solid electrolyte interface [40]. The straight line at low frequency corresponds to the linear diffusion process, which is called Warburg diffusion [38]. The introduction of the interlayer dramatically decreases the interfacial resistance from 175.1 to $32.92 \Omega$, indicating that the interlayer plays a crucial role in reducing the charge transfer resistance and enhancing solid/solid interface compatibility [41].

In addition, the influence of the interlayer thickness (20, 40 and 80 $\mu \mathrm{m})$ on the battery performance was investigated, and the results are displayed in Fig. 6c. The three batteries show the similar cycling performances. However, the battery with the interlayer thickness of 40 $\mu \mathrm{m}$ has the highest initial discharge capacity of $1495.6 \mathrm{mAh} \mathrm{g}^{-1}$ and the capacity of $1057.5 \mathrm{mAh} \mathrm{g}^{-1}$ after 20 cycles. So, the interlayer thickness of $40 \mu \mathrm{m}$ was used during the electrochemical performance measurements. 
The electrochemical kinetic processes of the batteries with the same cathode of $\mathrm{S}_{60} \mathrm{C}_{30} \mathrm{PAA}_{10}$ and with/without the interlayer at $80{ }^{\circ} \mathrm{C}$ were studied with cyclic voltammetry $(\mathrm{CV})$ at a scan rate of $0.2 \mathrm{mV} \mathrm{s}^{-1}$ between 2.8 to $1.5 \mathrm{~V}$, as shown in Fig. $6 \mathrm{~d}$ and Fig. $6 \mathrm{f}$. In the first cathodic scan of the battery with interlayer, there are three reduction peaks corresponding to the multistep reduction of elemental sulfur [42]. The position of the first peak at $2.39 \mathrm{~V}$ corresponds to the conversion of elemental sulfur to high-order polysulfides. In the following cycles, this peak shifts to a higher potential, which is due to a rearrangement of the active sulfur and reduced polarization [43]. Unlike typical CV curves of a liquid electrolyte Li-S battery [44], a peak at $2.11 \mathrm{~V}$ is observed, which is associated with the reduction of the higher-order polysulfides to the medium-order polysulfides [45]. The third peak at $1.99 \mathrm{~V}$ can be attributed to the formation of sulfides from polysulfides. In the following anodic scan, the two adjacent oxidation peaks at 2.35 and $2.47 \mathrm{~V}$ demonstrate the reverse reaction from lithium sulfide to polysulfides and then to elemental sulfur in the charging process. After the first scan, no significant changes are observed for either of the anodic/cathodic peak positions or current intensity, indicating a high electrochemical stability. Compared to the battery without interlayer, sharper redox peaks are observed, implying that the lithium ions and electrons can flow readily through the cathode and accelerate the kinetics processes of the 
electrochemical reactions as discussed in the study [46].

The rate performances of the batteries are compared among $\mathrm{S}_{60} \mathrm{C}_{30} \mathrm{PAA}_{5} \mathrm{SPE}_{5}$ without the interlayer, $\mathrm{S}_{60} \mathrm{C}_{30} \mathrm{PAA}_{10}$ without the interlayer and $\mathrm{S}_{60} \mathrm{C}_{30} \mathrm{PAA}_{10}$ with the interlayer. As can be seen, the battery with the cathode of $\mathrm{S}_{60} \mathrm{C}_{30} \mathrm{PAA}_{10}$ and the interlayer has the best rate performance, as shown in Fig. 7. The average discharge capacity of $907.3 \pm 206.6 \mathrm{mAh} \mathrm{g}^{-1}$ at $0.1 \mathrm{C}$ for the five cycles is obtained. When the rates were increased to $0.5,1$ and $2 \mathrm{C}$, the average discharge capacities are $627.6 \pm 32.1,479.9 \pm 29.3$ and $339.2 \pm 27.5 \mathrm{mAh} \mathrm{g}^{-1}$, respectively. When the rate was back to $0.1 \mathrm{C}$, an average discharge capacity of 715.6 $\pm 18.5 \mathrm{mAh} \mathrm{g}^{-1}$ is retained. When the interlayer lacks, the rate performance of the battery with the same cathode $\left(\mathrm{S}_{60} \mathrm{C}_{30} \mathrm{PAA}_{10}\right)$ deteriorates, which only has the discharge capacity of $217.6 \pm 132.8 \mathrm{mAh}$ $\mathrm{g}^{-1}$ at $0.1 \mathrm{C}$ and the discharge capacity dropped to zero when the rate was switched to $0.5 \mathrm{C}$. When the rate was back to $0.1 \mathrm{C}$, the average discharge capacity is $225.7 \pm 78.0 \mathrm{mAh} \mathrm{g}^{-1}$ that is 3 times lower than the capacity with the interlayer.

For the battery based on $\mathrm{S}_{60} \mathrm{C}_{30} \mathrm{PAA}_{5} \mathrm{SPE}_{5}$, the average discharge capacity is $568.4 \pm 90.5 \mathrm{mAh} \mathrm{g}^{-1}$ at $0.1 \mathrm{C}$, and the average discharge capacities are $430.3 \pm 9.3,325.9 \pm 14.5$ and $153.8 \pm 26.4 \mathrm{mAh} \mathrm{g}^{-1}$, respectively at $0.5,1$ and $2 \mathrm{C}$. When the rate ran back to $0.1 \mathrm{C}$, the average discharge capacity is $511.5 \pm 13.8 \mathrm{mAh} \mathrm{g}^{-1}$. Hence, the effect of 
the interlayer is much stronger than the introduction of electrolyte into the cathode on enhancing the electrochemical performance of the battery.

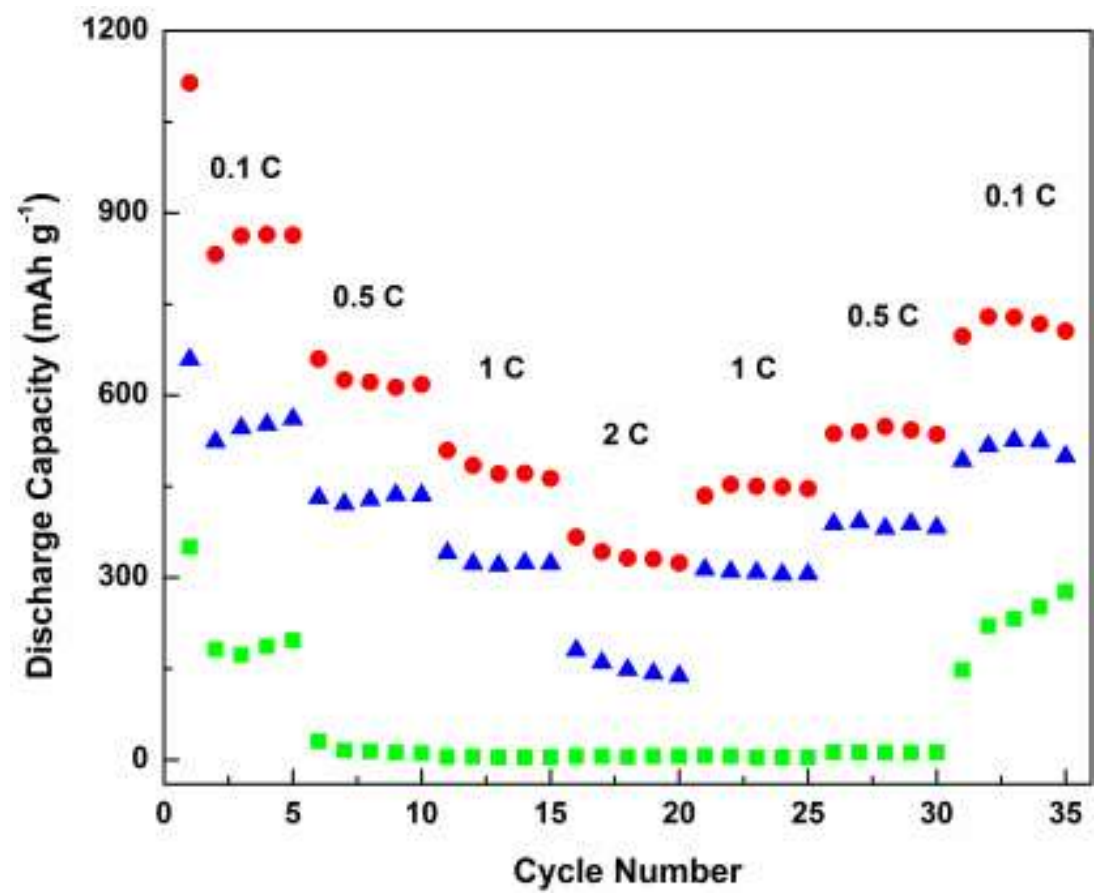

Fig. 7. Comparison of rate performances among three batteries at $60{ }^{\circ} \mathrm{C}$. Red circle: $\mathrm{S}_{60} \mathrm{C}_{30} \mathrm{PAA}_{10}$ with the interlayer, blue triangle: $\mathrm{S}_{60} \mathrm{C}_{30} \mathrm{PAA}_{5} \mathrm{SPE}_{5}$ without the interlayer, and green square: $\mathrm{S}_{60} \mathrm{C}_{30} \mathrm{PAA}_{10}$ without the interlayer.

\section{Conclusions}

An effective strategy of inserting a bifunctional ion-electron conducting interlayer between the cathode and SPE was used to improve the electrochemical performance of all-solid-state Li-S batteries. The introduction of the interlayer leads to gradual changes both of ionic and electronic conductivities at the interface instead of sudden changes. Thus high solid/solid interfacial compatibility is realized. The battery with the interlayer shows higher active material utilization and better cycling performance compared to the battery without the interlayer. The simultaneous introduction of interlayer and electrolyte into cathode will 
be investigated in further work.

\section{Acknowledgements}

This work was supported by the National Science Foundation of China (Grant no. 51274239), Grants from the Project of Innovation-driven Plan in Central South University, and the Fundamental Research Funds for the Central Universities of Central South University (No. 2016zzts285). 


\section{References}

[1] M. Armand, J.M. Tarascon, Building better batteries, Nature 451 (2008) 652-657.

[2] N. Choi, Z. Chen, S.A. Freunberger, X. Ji, Y. Sun, K. Amine, G. Yushin, L.F. Nazar, J. Cho, P.G. Bruce, Challenges facing lithium batteries and electrical double-layer capacitors, Angew. Chem. Int. Ed. 51 (2012) 9994-10024.

[3] D. Larcher, J.M. Tarascon, Towards greener and more sustainable batteries for electrical energy storage, Nat. Chem. 7 (2014) 19-29.

[4] A. Manthiram, Y. Fu, S.H. Chung, C. Zu, Y.S. Su, Rechargeable lithium-sulfur batteries, Chem. Rev. 114 (2014) 11751-11787.

[5] L.F. Nazar, M. Cuisinier, Q. Pang, Lithium-sulfur batteries, MRS Bull. 39 (2014) 436-442.

[6] A. Manthiram, Y. Fu, Y.S. Su, Challenges and prospects of lithium-sulfur batteries, Acc. Chem. Res. 46 (2013) 1125-1134.

[7] N.P. Deng, W.M. Kang, Y.B. Liu, J.G. Ju, D.Y. Wu, L. Li, B.S. Hassan, B. Cheng, A review on separators for lithium-sulfur battery: Progress and prospects, J. Power Sources 331 (2016) 132-155.

[8] A. Rosenman, E. Markevich, G. Salitra, D. Aurbach, A. Garsuch, F.F. Chesneau, Review on Li-sulfur battery systems: an integral perspective, Adv. Energy Mater 5 (2015) 1500212.

[9] M.A. Pope, I.A. Aksay, Structural design of cathodes for Li-S 
batteries, Adv. Energy Mater 5 (2015) 1500124.

[10] Z. Li, J.T. Zhang, Y.M. Chen, J. Li, X.W. Lou, Pie-like electrode design for high-energy density lithium-sulfur batteries, Nat. Commun. 6 (2015) 8850-8858.

[11] X.A. Chen, Z.B. Xiao, X.T. Ning, Z. Liu, Z. Yang, C. Zou, S. Wang, X.H. Chen, Y. Chen, S.M. Huang, Sulfur-impregnated, sandwich-type, hybrid carbon nanosheets with hierarchical porous structure for high-performance lithium-sulfur batteries, Adv. Energy Mater 4 (2014) 13072-13080.

[12] F. Wu, Y.S. Ye, R.J. Chen, J. Qian, T. Zhao, L. Li, W.H. Li, Systematic effect for an ultralong cycle lithium-sulfur battery, Nano Lett. 15 (2015) 7431-7439.

[13] X. Liang, Z.Y. Wen, Y. Liu, M.F. Wu, J. Jin, H. Zhang, X.W. Wu, Improved cycling performances of lithium sulfur batteries with $\mathrm{LiNO}_{3}$-modified electrolyte, J. Power Sources 196 (2011) 9839-9843.

[14] C. Huang, J. Xiao, Y.Y. Shao, J.M. Zheng, W.D. Bennett, D.P. Lu, L.V. Saraf, M. Engelhard, L.W. Ji, J.G. Zhang, X.L. Li, G.L. Graff, J. Liu, Manipulating surface reactions in lithium-sulphur batteries using hybrid anode structures, Nat. Commun. 5 (2014) 149-168.

[15] Y.S. Su, A. Manthiram, Lithium-sulphur batteries with a microporous carbon paper as a bifunctional interlayer, Nat. Commun. 3 (2012) $542-555$. 
[16] H.B. Yao, K. Yan, W.Y. Li, G.Y. Zheng, D.S. Kong, Z.W. Seh, V.K. Narasimhan, Z. Liang, Y. Cui, Improved lithium-sulfur batteries with a conductive coating on the separator to prevent the accumulation of inactive S-related species at the cathode-separator interface, Energy Environ. Sci. 7 (2014) 3381-3390.

[17] X.F. Wang, Z.X. Wang, L.Q. Chen, Reduced graphene oxide film as a shuttle-inhibiting interlayer in a lithium-sulfur battery, J. Power Sources $242(2013) 65-69$.

[18] J.Y. Hwang, H.M. Kim, S.K. Lee, J.H. Lee, A. Abouimrane, M.A. Khaleel, I. Belharouak, A. Manthiram, Y.K. Sun, High-energy, high-rate, lithium-sulfur batteries: synergetic effect of hollow $\mathrm{TiO}_{2}$-webbed carbon nanotubes and a dual functional carbon-paper interlayer, Adv. Energy Mater 6 (2016) 1501480.

[19] J.Q. Huang, Q. Zhang, F. Wei, Multi-functional separator/interlayer system for high-stable lithium-sulfur batteries: Progress and prospects, Energy Storage Materials 1 (2015) 127-145.

[20] X.W. Yu, Z.H Bi, F. Zhao, A. Manthiram, Hybrid lithium-sulfur batteries with a solid electrolyte membrane and lithium polysulfide catholyte, ACS Appl. Mater. Interfaces 7 (2015) 16625-16631.

[21] H.J. Peng, D.W. Wang, J.Q. Huang, X.B. Cheng, Z. Yuan, F. Wei, Q. Zhang, Janus separator of polypropylene-supported cellular graphene framework for sulfur cathodes with high utilization in lithium-sulfur 
batteries, Adv. Sci. 3 (2016) 1500268.

[22] C.H. Chang, S.H.Chung, A.Manthiram, Effective stabilization of a high-loading sulfur cathode and a lithium-metal anode in Li-S batteries utilizing SWCNT-modulated separators, Small 12 (2016) 174-179.

[23] Y.V. Mikhaylik, J.R. Akridge, Polysulfide shuttle study in the Li/S battery system, J. Electrochem. Soc. 151 (2004) A1969-A1976.

[24] S. Urbonaite, T. Poux, P. Novák, Progress towards commercially viable Li-S battery cells, Adv. Energy Mater 5 (2015) 1500118.

[25] J. Hassoun, B. Scrosati, Moving to a solid-state configuration: a valid approach to making lithium-sulfur batteries viable for practical applications, Adv. Mater. 22 (2010) 5198-5201.

[26] X. Liang, Z.Y. Wen, Y. Liu, H. Zhang, L.Z. Huang, J. Jin, Highly dispersed sulfur in ordered mesoporous carbon sphere as a composite cathode for rechargeable polymer Li/S battery, J. Power Sources 196 (2011) 3655-3658.

[27] C. Zhang, Y. Lin, J. Liu, Sulfur double locked by a macro-structural cathode and a solid polymer electrolyte for lithium-sulfur batteries, J. Mater. Chem. A 3 (2015) 10760-10766.

[28] A.S. Fisher, M.B. Khalid, M. Widstrom, P. Kofinas, Solid polymer electrolytes with sulfur based ionic liquid for lithium batteries, J. Power Sources 196 (2011) 9767-9773.

[29] G.M. Zhou, F. Li, H.M. Cheng, Progress in flexible lithium batteries 
and future prospects, Energy Environ. Sci. 7 (2014) 1307-1338.

[30] Y. Lin, J. Li, K. Liu, Y.X. Liu, J. Liu, X.M. Wang, Unique starch polymer electrolyte for high capacity all-solid-state lithium sulfur battery, Green Chem. 18 (2016) 3796-3803.

[31] N. Machida, H. Maeda, H. Peng, T. Shigematsu, All-solid-state lithium battery with $\mathrm{LiCo}_{0.3} \mathrm{Ni}_{0.7} \mathrm{O}_{2}$ fine powder as cathode materials with an amorphous sulfide electrolyte, J. Electrochem. Soc. 149 (2002) A688-A693.

[32] W.W. Cai, Y.F. Zhang, J. Li, Y.B. Sun, H.S. Cheng, Single-ion polymer electrolyte membranes enable lithium-ion batteries with a broad operating temperature range, ChemSusChem 7 (2014) 1063-1067.

[33] F.D. Han, J. Yue, X.L. Fan, T. Gao, C. Luo, Z.H. Ma, L.M. Suo, C.S. Wang, High-performance all-solid-state lithium-sulfur battery enabled by a mixed-conductive $\mathrm{Li}_{2} \mathrm{~S}$ nanocomposite, Nano Lett. 16 (2016) $4521-4527$.

[34] K. Zhu, Y. Liu, J. Liu, A fast charging/discharging all-solid-state lithium ion battery based on PEO-MIL-53(Al)-LiTFSI thin film electrolyte, RSC Adv. 4 (2014) 42278-42284.

[35] B.J. Neudecker, W. Weppner, $\mathrm{Li}_{9} \mathrm{SiAlO}_{8}$ : a lithium ion electrolyte for voltages above 5.4 V, J. Electrochem. Soc. 143 (1996) 2198-2203.

[36] C. Lau, Y.L. Mi, A study of blending and complexation of poly(acrylic acid)/poly(vinyl pyrrolidone), Polymer 43 (2002) 823-829. 
[37] M.A. Ratner, P. Johansson, D.F. Shriver, Polymer electrolytes: ionic transport mechanisms and relaxation coupling, MRS Bull. 45 (2000) $31-37$.

[38] Y.J. Choi, Y.D. Chung, C.Y. Baek, K.W. Kim, H.J. Ahn, J.H. Ahn, Effects of carbon coating on the electrochemical properties of sulfur cathode for lithium/sulfur cell, J. Power Sources 184 (2008) 548-552.

[39] Y.Z. Fu, A. Manthiram, Enhanced cyclability of lithium-sulfur batteries by a polymer acid-doped polypyrrole mixed ionic-electronic conductor, Chem. Mater. 24 (2012) 3081-3087.

[40] L.X. Yuan, X.P. Qiu, L.Q. Chen, W.T. Zhu, New insight into the discharge process of sulfur cathode by electrochemical impedance spectroscopy, J. Power Sources 189 (2009) 127-132.

[41] Y.S. Su, A. Manthiram, A new approach to improve cycle performance of rechargeable lithium-sulfur batteries by inserting a free-standing MWCNT interlayer, Chem. Commun. 48 (2012) 8817-8819.

[42] L. Qie, A. Manthiram, A facile layer-by-layer approach for high-areal-capacity sulfur cathodes, Adv. Mater. 27 (2015) 1694-1700. [43] R.J. Chen, T. Zhao, J. Lu, F. Wu, L. Li, J.Z. Chen, G.Q. Tan, Y.S. Ye, K. Amine, Graphene-based three-dimensional hierarchical sandwich-type architecture for high-performance Li/S batteries, Nano Lett. 13 (2013) 4642-4649. 
[44] Y.X. Yin, S. Xin, Y.G. Guo, L.J. Wan, Lithium-sulfur batteries: electrochemistry, materials, and prospects, Angew. Chem. Int. Ed. 52 (2013) 13186-13200.

[45] C. Barchasz, F. Molton, C. Duboc, J.C. Leprêtre, S. Patoux, F. Alloin, Lithium/sulfur cell discharge mechanism: an original approach for intermediate species identification, Anal. Chem. 84 (2012) 3973-3980. [46] Z.Q. Li, C.X. Li, Z.W. Zhang, X.L. Ge, J.Y. Ma, Q. Li, C.X. Wang, L.W. Yin, Reduced graphene oxide wrapped MOFs-derived cobalt-doped porous carbon polyhedrons as sulfur immobilizers as cathodes for high performance lithium sulfur batteries, Nano Energy 23 (2016) 15-26. 